\title{
A Study on Small Group Painting Art Therapy in Improving Self-esteem and Social Skills of Children with Depressive Tendency
}

\section{우울성향이 있는 아동이 자아존중감 및 사회성 향상을 위한 소집단 미술치료 사례연구}

Seong Mi $\operatorname{Sin}^{1}$

신성미 ${ }^{1}$

${ }^{I}$ Student Ph.D., Department of Human Care, Addiction Rehabilitation Counseling, Namseoul University Graduate School, Doctoral Program, Korea, smshin1234@naver.com

\begin{abstract}
The purpose of this study is to improve self-esteem and sociality by implementing art therapy programs for children with difficult peer relationships. To verify the results of self-esteem and sociality, the self-esteem test and the HTP tree drawing test were conducted, and social skills tests and KSD tests were conducted to compare and analyze pre- and post-change. Also, based on the program progress data, changes in self-esteem and sociality were organized step by step. The self-esteem test was reconstructed by Choi Bo-ga and Jeon Gwi-yeon (1993), and the social test used the Social Skill Rating System-Teacher Pom Elementary Level (SSRS), which was validated by Kim Hyang-ji (1996). Based on the results of the study, the following conclusions were drawn. First, small group art therapy had a slight positive effect on the self-esteem of children with a depression tendency. In the pre-score of self-respect tests, A children rose slightly from 88 points to 89 points, and children B rose slightly from 93 to 96 , but partially decreased in the lower areas. Second, through small group art therapy, the sociality of children with a tendency to depress was improved. In the sociality testing, children A increased from 25 to 42 points, while children B improved from 18 to 29 .
\end{abstract}

Keywords: Depressive Children, Self-esteem, Sociality, Small Group Art Therapy

요약: 본 연구의 목적은 또래 관계가 어려운 아동을 위한 미술 치료 프로그램을 시행하여 자 존감과 사회성을 향상하는 것입니다. 자아존중감과 사회성 연구 결과 검증을 위하여 자아존중 감 검사와 $\mathrm{HTP}$ 의 나무 그림 검사를 하였고, 사회성 기술검사와 $\mathrm{KSD}$ (학교 생활화) 검사를 하 여 사전•사후 변화를 비교•분석하였다. 또한 프로그램 진행 과정 자료를 바탕으로 자아존중감 및 사회성 변화를 단계별로 정리하였다. 자아존중감 검사는 최보가와 전귀연(1993)이 재구성 하여 만든 척도를 사용하였으며, 사회성 검사는 김향지(1996)가 타당성을 검증한 사회성 기술 검사(Social Skill Rating System-Teacher Fonm Elementary Level: SSRS)를 사용하였다. 본 연구 에서 밝혀진 결론은 다음과 같다. 첫째, 소집단 미술치료를 통하여 우울 성향이 있는 아동의 자아존중감에 미미하게 긍정적인 영향을 주었다. 자아존중감 검사 사전 점수에서 A 아동은 88점에서 89점으로 미미하게 상승하였으며, B 아동은 93에서 96으로 미미하게 상승하였으나 하위영역에서 부분적으로 하락하는 결과가 나타났다. 둘째, 소집단 미술치료를 통하여 우울 
성향이 있는 아동의 사회성이 높아졌다. 사회성 기술검사에서 A 아동은 25점에서 42점으로 상승하였으며, B 아동은 18점에서 29점으로 향상하였다.

핵심어:우울성향 아동, 자아존중감, 사회성, 소집단 미술치료

\section{1. 서론}

\section{1 연구의 필요성 및 목적}

인간은 누구나 사회를 살아가면서 수없이 많은 기분의 변화를 느낀다. 즐거움, 행복감, 자신감, 충만한 의욕 등 들뜨는 기분을 느낄 때가 있고 때로는 실패, 좌절, 불행감, 무가 치함 등 가라앉는 기분을 느낄 때가 있다. 이러한 변화는 인생의 과정에서 누구나 느낄 수 있지만, 그 정도가 심하지 않아 생활에서는 지장을 주지 않는다. 하지만 때로는 정도 가 심해서 일상생활에 불편함과 어려움을 겪으며, 불안정하거나 산만해지는 등 여러 가 지 부적응 문제를 유발하고 심하면 자살과 같은 치명적인 결과를 초래할 수도 있는 것이 우울이다[1].

우울(Depression)은 슬픔, 무기력, 공허감, 주관적인 불행감 등 기분이 저조한 상태로 일 상생활에서의 정신적인 기분 저하 상태를 나타내며, 식욕감소, 체중감소, 성욕감소 등 신 체적, 인지적 증상을 보이는 정서변화의 넓은 범주를 포함하고 있다.

그러한 우울 증상은 아동에게도 나타나며 성인보다 장기간 지속하고 재발률도 높다. 인 지적, 정서적으로 미성숙한 아동의 경우 심각한 우울을 경험하게 되면 성인보다 더 많은 혼란을 가져오게 된다[2]. 그런데 아동의 우울은 간접적이며 숨겨진 양상을 띠는 가면성 우울(masked depression)로 나타나기도 하는데, 아동이 스스로 자신의 심리적 어려움을 인 식하지 못하는 경우가 많음으로 이러한 정서적, 인지적, 신체적 증상을 보이는 우울 아동 은 사회생활에 어려움을 경험 할 수 있다.

특히 아동기는 여러 가지 발달과업을 습득하고 수행해야 하는 시기인데 이 시기에 우 울증이 생기면 인지•정서 및 학업능력, 대인관계 형성능력과 사회적 유능감 그리고 스트 레스 대처 양식의 습득 등 다양한 발달영역에 부정적인 영향을 받게 된다(주경애 2009). 우울함이 반복적으로 나타나면, 의욕 저하와 사기 저하로 무가치함을 경험하고 자기 질 책으로 인해 자아존중감이 낮아진다[3-5]. 아동기 후반기에서는 점차 청소년기와 성인기 에서 나타나는 죄책감, 자기비하, 자아존중감의 저하 등으로 일시적인 증상이 나타나기도 하고, 부정적인 미래상을 갖고 있으며 두통이나 복통 등과 같은 신체증상을 호소하기도 한다[6].

이처럼 우울 성향이 있는 아동은 즐거움을 느끼는 것에 어려움 있으며, 사회적으로 위 축되어 있어 자아존중감이 낮고 활동력 저하로 또래와 교사와의 관계 나아가 사회생활의 전반적으로 적응하는 데 있어서 어려움을 격음으로 우울과 자아존중감은 서로 밀접한 연 관성이 있으며 나아가 아동의 사회성과도 연결이 된다.

김하경(1988)은 학급 내에서 우울감으로 위축되고 고립된 아동은 남과 잘 어울리지 못 하고 자기 의사표시를 잘 못 하며 자기 권리를 찾지 못한다고 하였다. 그리고 우울하며, 공격성이 높아지고, 수동공격, 도벽, 훼방, 거짓말 등 우울 아동의 학교생활 부적응을 보 고하였다. 이처럼 우울 아동은 또래 관계, 교사와의 관계, 학업 성적 등 학교생활에 전반 적으로 적응하면서 어려움을 겪는다. 
이러한 학교생활의 어려움을 겪는 아동의 심리적 어려움을 치료하기 위해 놀이 치료, 인지행동치료, 행동 치료, 음악치료, 미술치료 등 다양한 상담 및 심리 치료적 접근 방법 들을 활용하고 있다. 그중에서 미술치료는 쉽게 접근 가능한 매체를 활용하여 자발적인 참여를 통해 억압된 감정과 욕구를 상징적인 이미지로 표출 할 수 있다[7]. 또한 비언어 적 의사소통으로, 신체적, 정신적으로 고통 받는 사람들의 긴장을 해소해주고 건강한 신 체와 정서적 안정을 제공할 수 있다.

우울 아동에게 집단미술치료는 미술 활동을 하면서 집단 구성원 간에 자연스럽게 상호 작용이 증진되고 작품을 만드는 과정을 통해 문제를 인식하며, 완성된 작품을 보면서 성 취감을 느끼게 하고 자기를 개방하고 표현을 함으로써 집단원간의 신뢰와 함께 긍정적인 대인관계를 형성하게 되어 사회적 기능을 촉진한다. 또한 집단 활동을 통해 집단원들 간 의 지지와 정서적 유대감 및 소속감을 경험함으로써 자신의 문제를 새로운 각도에서 인 식할 수 있다. 그리고 집단 활동을 통해 부정적인 감정 표출하고 해소 할 수 있고 자기 이해와 자기표현을 할 수 있으며, 작품 활동을 통해 자신감을 성취하고 스트레스 감소 및 사회적 기술을 배울 수 있다[8-10].

본 연구에서는 집단미술치료, 소집단 미술치료에 관한 선행연구와 같이 소집단 미술치료가 우울 성향이 있는 아동의 자아존중감 및 사회성에 미치는 긍정적 영향을 알아보는 것에 그 의의를 두고 있다.

\section{2 연구문제}

첫째, 소집단 미술치료가 우울성향이 있는 아동의 자아존중감에 어떤 영향을 미치는가? 둘째, 소집단 미술치료가 우울성향이 있는 아동의 사회성에 어떤 영향을 미치는가? 셋째, 소집단 미술치료 회기별 진행과정에서의 자아존중감 및 사회성 변화는 어떠한가?

\section{2. 연구방법}

\section{1 연구설계}

본 연구는 실험집단의 사전 - 사후 비교를 하는 사전 사후검사설계로서 실험집단에 소 집단 미술치료를 실시한 후 사전 - 사후 검사로 자아존중감 검사, 나무 그림 검사와 사회 성 기술검사, $\mathrm{KSD}$ 그림검사를 실시하였다.

본 연구의 설계는 독립변인을 소집단 미술치료로 하고 종속 변인을 자아존중감과 사회 성으로 하였다.

\section{2 연구대상}

본 연구는 $\mathrm{D}$ 시내의 $\mathrm{A}$ 지역아동센터를 이용하는 초등학교 5,6 학년 아동으로 한국 아 동 성격검사(Korean Child Personality Inventory for Teachers : KCPI-T)척도의 하위 영역인 우울 에서 $\mathrm{T}$ 점수 70 이상인 아동이며, 사회성 기술검사(Social Skill Rating System-Teacher Fonm Elementary Level: SSRS)의 점수가 30점 이하인 아동이다.

\section{3 측정도구}




\subsection{1 자아존중감 검사}

자아존중감 척도는 자기 존중 정도와 자아 승인 양상을 측정하는 검사로서, Coopersmith(1967)의 문항을 최보가 와 전귀연(1993)이 재구성하여 만든 자아존중감 척도를 사용하였으며, 신뢰도는 하위척도별 Cronbach-a 계수 .69-.84범위로 만족할 만한 수준이며 학교 자아존중감 8 문항은 역채점 문항이다.

\subsection{2 나무그림 검사}

1948년 HTP 검사를 개발한 벅(John Buck)은 나무는 자연 세계에 대한 자아의 적응양식 표현이라고 했으며, 무의식적 자아상, 성숙도 등을 알 수 있음으로 나무의 상장은 자아와 관련지어진다.

\subsection{3 사회성 기술검사(교사용)}

사회성 기술검사(Social Skill Rating System-Teacher Fonm Elementary Level: SSRS)는 Gresham과 Elliott(1990)의 사회성 기술 검사로 일반아동과 정신지체아동에 대한 표준화가 마련된 것으로 김향지(1996)가 타당성 검증을 한 것으로 문항 양호도는 $1 \%$ 수준 신뢰도는 .85 이다.

\subsection{4학교생활화(KSD:Kinetic School Drawing)}

학교생활화(KSD : Kinetic School Drawing)는 동적가족화(KFD : Kinetic Family Drawing)를 보충하기 위해 Knoff와 Prout(1974)에 의해 처음으로 소개되었으며 학교에 관한 학업 인식이나 그 밖의 자기인식, 아동의 교사상, 친구상과 친구 관계를 파악하는 데 유용하다.

\section{4 소집단 미술치료프로그램}

단계별 목표는 1 단계(1 3회기) 친밀감 형성 및 흥미 유발, 2단계(4 7회기)는 미술 매체를 활용한 창작활동으로 자기 탐색과 인식을 통한 자기표현 및 자기주장, 3 단계(8 11회기) 자아 통제 및 협력, 4단계(12 15회기) 협력을 통하여 사회성 향상으로 구성하였다. 1 회기부터 7 회기까지는 주제와 매체를 제시해줌으로써 안정감을 느끼고 집단 원과 친밀감을 형성하고 자기표현을 할 수 있도록 구성하였고, 8 회기부터 15 회기까지는 여러 가지 매체를 제시해주고 아동이 선정한 매체를 중심으로 주제를 제시해주는 구조화로 총 15 회기로 구성하였다.

\section{5 자료 분석 방법}

소집단 미술치료가 우울 성향이 있는 아동의 자아존중감 및 사회성에 미치는 영향을 알아보기 위해 자아존중감 검사와 나무 그림 검사를 실시하였고, 사회성을 알아보기 위해 사회성 기술검사와 $\mathrm{KSD}$ (학교 생활화) 검사를 하여 사전•사후 변화를 비교•분석하였다.

\section{3. 연구 결과}

\section{1 자아존중감 변화 결과}

\subsubsection{A연구대상}


자아존중감 검사 : 자아존중감 검사는 일반적 자아존중감, 사회적 자아존중감, 가정적 자아존중감, 학교 자아존중감의 4 개의 하위요인으로 총 32 문항으로 구성되어 있으며, 점 수가 높을수록 자아존중감이 높은 것을 의미한다. 전체 자아존중감 사전점수가 88 에서 89로 1점 상승하였으며, 하위요인에 따른 문항을 분석해 보면 일반적 자아존중감은 2점 하락하였고 사회적 자아존중감은 2점 상승하였다. 그리고 가정적 자아존중감은 3 점 하락 하였고 학교 자아존중감은 3점 상승하였다.

변화에 대한 결과는 다음 [표 1]을 통해 사전•사후 전체 자아존중감과 하위요인에 변화를 알 수 있다.

[표 1] 자아존중감 검사 사전,사후 변화

[Table 1] Changes Before and After the Self-esteem Test

\begin{tabular}{|c|c|c|}
\hline & 사전 & 사후 \\
\hline 전체 자아존중감 & 88 & 89 \\
\hline 일반적 자아존중감 & 18 & 17 \\
\hline 사회적 자아존중감 & 26 & 28 \\
\hline 가정적 자아존중감 & 21 & 18 \\
\hline 학교 자아존중감 & 23 & 26 \\
\hline
\end{tabular}

나무그림 검사 사전•사후 비교를 통해 자아존중감 변화를 알 수 있다.

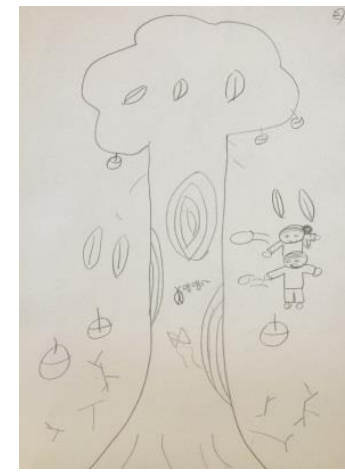

[그림 1] 나무그림 사전

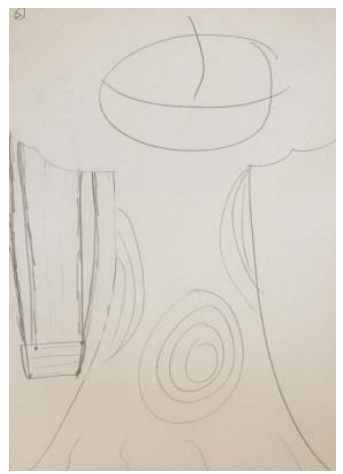

[그림 2] 나무그림 사후

[Fig. 1] Tree Drawing Test Dictionary [Fig. 2] Tree Drawing Test Post Inspection

사전 : 가지의 생략은 위축감을 나타내며, 나뭇잎과 열매가 땅에 떨어져 있는 것은 타 인과의 상호작용에서 좌절, 정서적 어려움을 나타낸다. 나무 외에(열매, 꽃, 동물, 그네 등) 다른 것을 더 그려 넣는 경우 불안을 보상하려는 욕구, 사랑과 관심을 받고 싶어 함 을 나타낸다.

사후 : 현저하게 큰 줄기는 환경에 대하여 적극적으로 움직이며 행동하려는 경향을 나타 낸다. 줄기가 짧고 수관이 큰 나무 그림은 자신감을 가지고 정열적으로 사물에 몰두하는 사람에게서 자주 나타난다. 사전 검사 질문에서 병들어 있었는데 사후 검사 질문에서는 건강해졌다고 대답한 것으로 보아 자아상이 긍정적으로 바뀌어 자아존중감이 향상된 것 으로 보인다. 


\subsubsection{B연구대상}

자아존중감 검사 : 자아존중감 검사는 일반적 자아존중감, 사회적 자아존중감, 가정적 자아존중감, 학교 자아존중감의 4 개의 하위요인으로 총 32 문항으로 구성되어 있으며, 점 수가 높을수록 자아존중감이 높은 것을 의미한다. 전체 자아존중감 사전점수가 93에서 96으로 3점 상승하였으며, 하위요인에 따른 문항을 분석해 보면 일반적 자아존중감은 2 점 상승하였고 사회적 자아존중감은 2점 하락하였다. 그리고 가정적 자아존중감은 2점 상승하였고 학교 자아존중감은 1점 상승하였다.

변화에 관한 결과는 다음 [표 2]를 통해 사전•사후 전체 자아존중감과 하위요인에 변화 를 알 수 있다.

[표 2] 자아존중감 검사 사전,사후 변화

[Table 2] Changes Before and After the Self-esteem Test

\begin{tabular}{|c|c|c|}
\hline & 사전 & 사후 \\
\hline 전체 자아존중감 & 93 & 96 \\
\hline 일반적 자아존중감 & 16 & 18 \\
\hline 사회적 자아존중감 & 25 & 23 \\
\hline 가정적 자아존중감 & 28 & 30 \\
\hline 학교 자아존중감 & 24 & 25 \\
\hline
\end{tabular}

나무그림 검사 사전-사후 비교를 통해 자아존중감 변화를 알 수 있다.

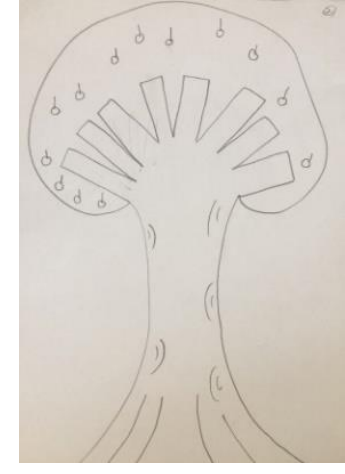

[그림 3] 나무그림 사전

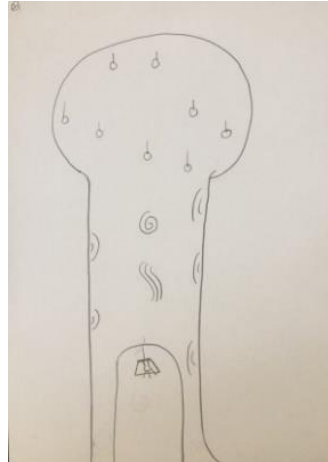

[그림 4] 나무그림 사후

[Fig. 3] Tree Drawing Test Dictionary

[Fig. 4] Tree Drawing Test Post Inspection

사전 : 잘린 가지는 자기의 발전과 활동이 억제되어있다고 느끼고 있음을 나타내며, 줄 기보다 현저하게 큰 가지는 환경에서 만족을 얻기 위해 지나치게 노력을 하는 부적절함 을 나타내며 근본적으로 무력감을 가진 것을 나타낸다.

사후 : 열쇠 구멍과 같은 나무는 반항기의 아동에게 자주 보이는 것으로 성격이 경직되 어 있고 강한 적대감을 가지고 있는 경우 나타낸다. 공 모양 수관은 공상, 마음이 빈 현 실에 대한 저항을 나타낸다. 전체적으로 필압이 강해졌으며 친구와 함께 살며 공간도 넓 고 건강하다고 한 것으로 보아 자아 강도가 향상된 것으로 보인다. 


\section{2 사회성 변화 결과}

\subsubsection{A연구대상}

사회성 기술검사는 자아 통제, 자기주장, 협력의 3 개의 하위요인으로 총 30 문항으로 구 성되어 있으며, 점수가 높을수록 사회성이 높은 것을 의미한다. 전체 사회성 기술검사 점수가 25점에서 42점으로 상승하였으며, 하위요인에 따른 문항을 분석해 보면 자아 통 제는 5점 상승하였고 자기주장은 8점 상승하였으며 협력은 3점 상승하였다.

변화에 대한 결과는 다음 [표 3]을 통해 사전-사후 전체 사회성과 하위요인에 변화를 알 수 있다.

[표 3] 사회성 기술 검사 사전,사후 변화

[Table 3] Changes Before and After the Social Skills Test

\begin{tabular}{|c|c|c|}
\hline & 사전 & 사후 \\
\hline 전체 & 25 & 42 \\
\hline 자아통합 & 10 & 15 \\
\hline 자기주장 & 6 & 14 \\
\hline 협력 & 9 & 12 \\
\hline
\end{tabular}

$\mathrm{KSD}$ 검사 사전, 사후 비교를 통해 사회성 변화를 알 수 있다.

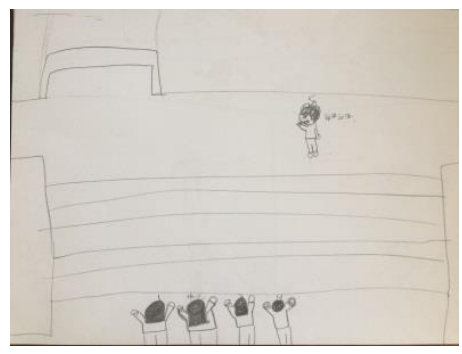

[그림 5] KSD 사전

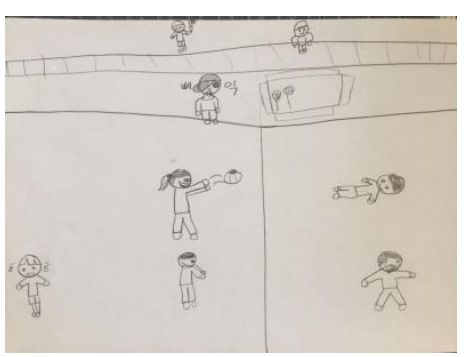

[그림 6] KSD 사후

[Fig. 5] Per-KSD

[Fig. 6] Post- KSD

사전 : 필압이 대체적으로 조금 약한 편이며, 크기가 작고 자신과 친구들이 하단에 있 으며 선생님은 상단에 있다. 자신과 친구들의 뒷모습을 그렸으며 다리가 잘려있으며 선 생님의 표정은 화가 나 있는 듯 보인다.

사후 : 필압이 전체적으로 강해졌으며, 사람을 많이 그렸으며 나의 표정은 밝은 표정이 며, 다른 일부 친구들의 표정도 웃는 표정으로 그려주었다. 자신을 중앙에 배치하고 인물 의 크기도 조금 커졌으며 여러 명의 친구와 피구를 하며 친구들과 상호작용한 것을 표현 해 준 것으로 보아 사회성이 높아진 것으로 보인다. 


\subsubsection{B연구대상}

사회성 기술검사는 자아 통제, 자기주장, 협력의 3 개의 하위요인으로 총 30 문항으로 구 성되어 있으며, 점수가 높을수록 사회성이 높은 것을 의미한다. 전체 사회성 기술검사 점수가 18점에서 29점으로 상승하였으며, 하위요인에 따른 문항을 분석해 보면 자아 통 제는 6점 상승하였고 자기주장은 3점 상승하였으며 협력은 3점 상승하였다.

변화에 대한 결과는 다음 [표 4]를 통해 사전•사후 전체 사회성과 하위요인에 변화를 알 수 있다.

[표 4] 사회성 기술 검사 사전,사후 변화

[Table 4] Changes Before and After the Social Skills Test

\begin{tabular}{|c|c|c|}
\hline & 사전 & 사후 \\
\hline 전체 & 18 & 29 \\
\hline 자아통합 & 10 & 16 \\
\hline 자기주장 & 4 & 7 \\
\hline 협력 & 4 & 7 \\
\hline
\end{tabular}

$\mathrm{KSD}$ 검사 사전, 사후 비교를 통해 사회성 변화를 알 수 있다.

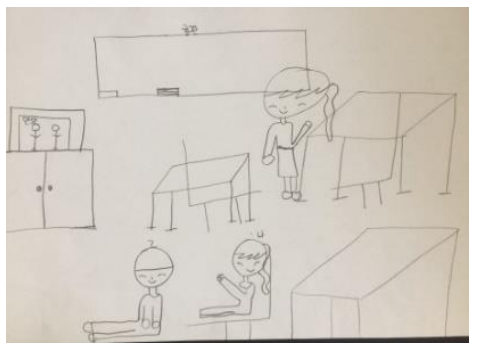

[그림 7] KSD 사전

[Fig. 5] Per-KSD

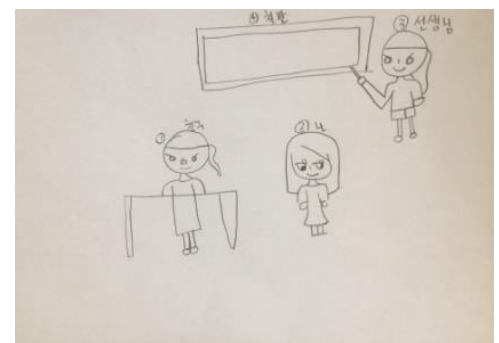

[그림 8] KSD 사후

[Fig. 6] Post- KSD

사전 : 나와 친구는 하단에 그렸으며 선생님은 약간 위쪽 우측에 그려주었다. 나는 의 자로 기저선을 그려주었다. 발과 한쪽 팔은 생략을 해주었다. 책상과 의자 선생님의 머리 부분을 선을 겹쳐 표현해 주었다.

사후 : '나'와 친구를 중앙에 그렸으며 선생님은 위, 오른쪽에 그려주었다. 선생님과 친구 의 표정은 불친절하며 화가 나 있는 듯 보인다. 친구의 팔과 손이 생략되어 있으며 '나' 는 발이 생략되었으나 인물의 크기도 커지고 교실에서 수업하는 모습을 표현했다.

\section{4. 결론}

본 연구에서 우울 성향이 있는 아동이 소집단 미술치료를 함으로써 자아존중감 및 사 회성을 상승시키는 것에 목적이 있다. 연구 대상자는 $\mathrm{D}$ 시내의 $\mathrm{A}$ 지역아동센터를 이용하 는 초등학교 5,6 학년 아동으로 한국 아동 성격검사(KCPI-T)척도의 하위 영역인 우울에서 
$\mathrm{T}$ 점수 70 이상인 아동이며, 사회성 기술검사(SSRS)의 점수가 30 점 이하인 아동이다.

사전•사후 비교를 위해 사전에 실험집단에 자아존중감 검사, 나무 그림 검사와 사회성 기술검사, $\mathrm{KSD}$ 그림검사를 실시하고 소집단 미술치료를 실시한 후 사후 검사로 자아존중 감 검사, 나무 그림 검사와 사회성 기술검사, $\mathrm{KSD}$ 그림검사를 실시하였다.

본 연구 결과를 바탕으로 다음과 같은 결론을 얻었다.

첫째, 소집단 미술치료가 우울 성향이 있는 아동의 전체 자아존중감은 미미하게 상승하 는 변화를 보였으나 하위영역에서는 부분적으로 향상되는 결과가 나타났다. 그리고 나무 그림 검사에서도 그림의 변화된 것을 통하여 대상 아동들의 자신감과 자아존중감이 향상 한 것을 알 수 있다. 이는 아동들이 다루기 쉬운 매체를 구성하고 1,2 단계인 1 회기부터 7 회기까지는 대상 아동 2 인으로 개별작업으로 진행하며, 작품을 보고 서로 긍정적인 지 지를 받고 작품 발표를 함으로써 자신감을 회복하여 자아존중감이 향상되었다고 사료된 다.

둘째, 소집단 미술치료가 우울 성향이 있는 아동의 사회성 향상을 사회성 기술검사에서 향상되는 결과가 나타났다. 그리고 $\mathrm{KSD}$ (학교 생활화)에서도 그림이 커지고 웃는 표정으 로 표현하였으며 피구를 하는 것으로 표현해 줌으로써 타인과 상호작용하는 모습으로 표 현해 주는 등 변화된 그림을 통해 자신감과 자아존중감이 향상하여 사회성이 향상된 것 을 알 수 있다.

이는 3,4 단계인 8 회기부터 15 회기까지 협력 아동 4 인을 포함하여 총 6 인으로 구성하여 대상 아동이 원하는 매체로 프로그램을 구성하여 협동작업을 통해 집단 원들과 함께 제 작하는 과정에서 응집력이 생기고, 이야기 나누기 과정을 거쳐 자기 통찰을 하며 자기조 절을 할 수 있게 되었다. 타인을 이해하며 공감하고 서로 집단 원들과의 상호작용으로 인하여 자신감이 생기고 자아존중감의 향상과 더불어 대인관계가 원만해짐으로써 사회성 이 향상되었다고 사료된다.

따라서 본 연구의 소집단 미술치료 프로그램은 자아존중감 및 사회성 향사에 효과적인 프로그램이다.

이상의 연구 결론을 근거로 본 연구에 대한 제한점과 다음과 같은 제언을 하고자 한다. 본 연구에서는 아동의 자아존중감 및 사회성 향상에 대한 효과를 검증하기 위해 자기 평정 척도와 지역아동센터장의 척도 검사와 소집단 미술치료 과정에서 나타난 자아존중 감과 사회성의 변화를 비교하였다. 그러나 추후 연구에는 학교에서의 수업태도 및 또래 관계, 가정에서의 행동관찰 등 다양한 사회영역에 대한 정보를 추가하여 자아존중감과 사회성 향상에 대한 영향 분석과 효과 검증의 필요성이 요구된다.

또한, 지역아동센터에 학습프로그램과 여러 가지 문화 프로그램이 활성화되어있지만, 심리적인 위축, 높은 불안감, 낮은 자아존중감, 사회성이 부족 등 심리적으로 힘든 아동 들을 위한 심리진단 또는 치료에 관한 프로그램은 미비하므로 미술치료를 포함하여 다양 한 심리치료 프로그램의 개발이 요구된다.

\section{References}

[1] Seok-man Kwon, The second edition of modern ideal psychology, Seoul: Hakjisa, (2013)

[2] M. Kovac, T. L. Feinberg, M. Crouse-novak, S. L. Paulauskas, M. Pollock, R. Finkelstein, Depression disorders in childhood II, A longitudinal study of the risk for a subsequent major depression, Archives of General Psychiatry, 
(1984), Vol.41, No.7, pp.643-649, DOI: 10.1001/archpsyc.1984.01790180013001

[3] Yu-mi Kim, A Study on the Single Case Study of Art Therapy for Improvement of Self-Respect of Unconforming Children, Dongguk University, Master's Thesis, (2007)

[4] H. S. Yoo, Emotional and behavioral problems of runaway adolescents in youth shelters and their relationships with related variables, Department of Special Education Graduate Schoool of Chosun University, Doctoral Dissertation, (2016)

[5] J. S. Choi, S. C. Cho, Assessment of Anxiety in Childen- Reliability and Validity of Revised Children's Manifest Anxiety Scale-, J Korean Neuropsychiatr Assoc, (1990), Vol.29, No.3, pp.691-702.

[6] Hye-mi Sung, The Effects of Positive Psychological Therapy Program on Depression, Self-esteem, and Adjustment to School Life of Depressive Elementary School Students, Kyungsung University Graduate School of Education Master's Thesis, (2011)

[7] Yu-eun Kim, Effects of collective art therapy centered on cooperative work on children's emotional intelligence and social skills, Myongji University Graduate School of Social Education, Master's Thesis, (2016)

[8] Hyun-mi Roh, In-jeon Park, The Effect of Group Art Therapy on the Socio-emotional Loneliness and Isolation Children from Low-Income Families, Korean Journal of Art Therapy, (2008), Vol.15, No.3, pp.469-488, DOI: 10.35594/kata.2008.15.3.005

[9] Young-ok Yoon, Dong Yeon Kim, Effects of the Group Art Therapy on Behavior Problems of Old Man with Dementia, Korean Journal of Art Therapy, (2006), Vol.13, No.1, pp.115-141, UCI: G704-001532.2006.13.1.005

[10] Mi-ae Moon, (The) Effect of Group Art Therapy on the Decrease of Stress \& the Improvement of Adjustment of the Children in Low income, Seoul Women's University Graduate School of Special Therapy, Master's Thesis, (2006) 